\title{
Rui Namorado, nenhum lugar e sempre
}

\section{Graça Capinha}

\section{(2) OpenEdition}

\section{Journals}

\section{Edição electrónica}

URL: http://journals.openedition.org/rccs/1035

DOI: $10.4000 /$ rccs. 1035

ISSN: 2182-7435

\section{Editora}

Centro de Estudos Sociais da Universidade de Coimbra

Edição impressa

Data de publição: 1 junho 2005

Paginação: 171-175

ISSN: 0254-1106

\section{Refêrencia eletrónica}

Graça Capinha, «Rui Namorado, nenhum lugar e sempre », Revista Crítica de Ciências Sociais [Online]

71 | 2005, posto online no dia 01 outubro 2012, consultado o 22 setembro 2020. URL : http:// journals.openedition.org/rccs/1035; DOI : https://doi.org/10.4000/rccs.1035 


\section{Recensões}

\section{Moura, Tatiana, Entre Atenas e Esparta: Mulheres, paz e conflitos armados. Coimbra: Quarteto Editora, 2005, 114 pp.}

José Saramago dá início a muitas das suas narrativas colocando ses na história para a contar de outra maneira e assim apontar os mundos alternativos que sobre essa história se poderiam ter construído, projectando-os no nosso presente de construção de outros mundos possíveis. Como diz o narrador de Evangelho Segundo Jesus Cristo, "se a lei não tivesse feito calar as mulheres para todo o sempre talvez elas, porque inventaram aquele primeiro pecado de que todos os mais nasceram, soubessem dizer-nos o que nos falta saber". Com Entre Atenas e Esparta: Mulheres, paz e conflitos armados, Tatiana Moura convida-nos a levantar o véu sobre esse silêncio milenar das mulheres evocado por José Saramago, reflectindo sobre os motivos e as razões da lei que manteve as mulheres nesse silêncio, e constrói uma maneira alternativa de olhar o mundo, questionando assim o pensamento dominante em Relações Internacionais que tem sido, desde as suas origens, uma expressão masculina e particular do "sistema de guerra", como defende José Manuel Pureza no prefácio que dedica à obra. Se olhássemos as Relações Internacionais a partir do ponto de vista feminino? desafia-nos a autora. Antes de entrar nessa história tão cheia de ses históricos, políticos, sociais e sexuais, Tatiana Moura vai dar-nos uma panorâmica crítica informadíssima das visões e sensibilidades políticas que têm orientado as Relações Internacionais, mostrando-nos, por um lado, as diferentes matizes desta disciplina na sua reflexão sobre o poder e sobre os equilíbrios do poder a fim de evitar o conflito e, por outro lado, o carácter desequilibrado da reflexão das RI (numa disciplina que pretende entre outras coisas gerar equilíbrios) e da sua prática ao configurar-se de uma forma abusivamente masculina em termos de pensamento e acção.

Abordando as definições de político, e em particular as fronteiras da identidade política e da cidadania estabelecidas pelas práticas do Estado, de poder, nos seus vários significados e implicações nomeadamente o de configuração militar, onde a masculinidade faz parte integral da própria morfologia do poder, de violência, na sua dimensão clássica de conflito que conduz ao confronto, e de segurança, como um estado de equilíbrio de ostentação bélica entre Estados, Tatiana Moura questiona a limitação destas definições pelo muito que excluem. Rastreando a importância da crítica feminista a estas definições, ainda muito dominadas por uma abordagem essencialmente militarista, agressiva e competitiva - seja na definição de violência como guerra, seja na definição de segurança como acumulação de força bélica, seja ainda no exercício do poder como um poder sobre, e não, do poder com, como proporão as correntes feministas - Tatiana Moura lança os pilares de um paradigma outro construído a partir das mulheres e do olhar feminista, que claramente desmascara a estreiteza das definições apresentadas pelas Relações Internacionais para descrever o mundo actual. A desconstrução deste paradigma de análise, particularmente aplicado às questões da guerra e da paz é feita na primeira parte do livro intitulada "A desconstrução social da guerra e da paz”, onde 
a autora denuncia as camuflagens, os silêncios e os estereótipos que asseguram a perpetuação de um sistema assente em relações de poder desiguais e elabora uma visão crítica da evolução dos discursos institucionais sobre a presença e participação das mulheres em conflitos armados. $\mathrm{Na}$ segunda parte do livro, a investigadora situa a sua análise no período pós-conflito abordando a questão das "Mulheres e re(des)construção pós-bélica: entre os estereótipos e o reconhecimento", tendo como base de reflexão a acção e os documentos das Nações Unidas em operações de consolidação de paz. O tom interrogativo com que abre esta segunda parte dá-nos desde logo a ideia do muito (para não dizer do "quase tudo") que há para fazer: será que a ONU, na sua ânsia de aplicar o modelo padronizado de reconstrução pós-bélica, tem em conta os diferentes papéis e experiências do tecido social que pretende reestruturar? Será esta fase de reconstrução sinónimo de efectiva alteração dos padrões de dominação (étnica, sexual, económica ou política) que levaram ao conflito? Mas o que é porventura mais perturbador nestas interrogações de Tatiana Moura não é tanto a pergunta sobre o que não está inscrito nestes documentos mas sobre o que, de certa forma, neles se vislumbra. $\mathrm{O}$ acto revolucionário do olhar e da interrogação de Tatiana Moura está de facto na interrogação das efectivas e não inocentes áreas de silêncio destes documentos e destas acções, e dos motivos destes silêncios.

O livro abre com uma ideia paradoxalmente polémica e consensual ao dizer-nos, por outras palavras, que a expectativa de paz alimentada pelo final da Guerra Fria não se cumpriu. Pelo contrário, desde 1989 "temos vindo a assistir à perpetuação de conflitos e da violência global" (p. 7) e à emergência de novas formas de conflito que, ao trazerem de forma numerosa para o teatro de guerra a população civil, nos levam a uma reflexão mais profunda sobre as suas mais numerosas vítimas: mulheres e crianças, curiosamente o par social tão "protegido" pela ideologia político-militar masculina e em nome do qual se diz terem sido feitas tantas guerras, ditas clássicas. Por outro lado, e na análise conjugada de Tatiana Moura, o olhar dos estudos feministas para o mundo masculino das RI e das guerras, possibilitou uma redefinição das categorias acima referidas - o político, o poder, a violência e a segurança - agora mais largamente consideradas, sendo o político e o poder vistos muito mais para além de uma vida institucionalmente concebida, e a violência e a segurança muito mais além da sua mera expressão militar e bélica. Consequentemente, o próprio fenómeno da guerra foi repensado nas suas configurações e expressões e nos seus intervenientes e participantes de forma que a questão passou a fazer parte da agenda internacional.

Não se trata, portanto, de olhar para as periferias da guerra e do pós-guerra para aí encontrar as mulheres. A questão de Tatiana Moura vai muito além e começa por recusar esse papel tradicionalmente atribuído às mulheres de estar nas margens do sistema. Como bem sublinha a autora, hoje as mulheres estão no centro do conflito. São as suas maiores vítimas e, portanto, também deveriam estar no centro, a par dos homens, na reconstrução pós-bélica. Não há dúvida de que têm sido as correntes feministas - seja na vertente das RI, seja na vertente dos Estudos para a Paz - que mais têm criticado construtivamente o olhar masculino e estatocêntrico das Relações Internacionais. O seu precioso contributo para a crítica aos estereótipos que colocam o homem a fazer a guerra e a mulher a fazer a paz - e que assim perpetuam a construção social do sistema de guerra e viciam a reconstrução pós- 
-bélica - bem como o seu questionamento das definições de guerra e violência, por um lado, e de segurança e paz, por outro, permitem-nos ter algum capital de esperança, como mostra Tatiana Moura no percurso que traça do discurso político e institucional relativo às mulheres: primeiro, absolutamente neutral, havendo nessa neutralização não um reconhecimento, mas um efectivo não estatuto da mulher em questões de guerra, seguido de um discurso de vulnerabilidade da mulher face aos acontecimentos das guerras recentes, nomeadamente a guerra da ex-Jugoslávia, que elege a mulher como vítima passiva, até ao ponto de viragem com a plataforma de Pequim em 1995, em que é efectivamente reconhecido um estatuto político às mulheres no conflito e na reconstrução pós-bélica. É de facto aqui que, de um grupo alvo de assistência humanitária, as mulheres passam a ser um grupo que é preciso envolver na resolução de conflitos, passando-se assim a um discurso de necessidade de capacitação das mulheres, que faça delas agentes reconhecidos de mudança.

Tatiana Moura mostra-nos o caminho percorrido e, sobretudo, o muito que ainda se tem de percorrer, ao analisar criticamente a proposta de modelo padronizado de reconstrução pós-bélica das Nações Unidas, contido na Agenda para a Paz de 1992, de Boutros-Ghali. Como refere a autora, a reconstrução pós-bélica é um período crucial de reconfiguração das relações de poder em sociedades devastadas por conflitos. Hoje, verificamos que grande parte dos conflitos volta, por se ter falhado o pós-guerra, ou seja, os momentos cruciais de instalação e de regresso a uma certa normalidade que a guerra tinha interrompido. O discurso do pós-guerra reafirma as relações preexistentes entre os dois sexos com vista à paz social, o que implica sempre, em termos femininos, um recuo relativamente às posições adquiridas durante a guerra, pois o pós-guerra não traz por si só a alteração das relações patriarcais que caracterizam as sociedades, levando à efectiva transformação.

Numa crítica extremamente estimulante, Tatiana Moura persegue os quatro elementos base da reconstrução pós-bélica. Assim, no plano militar, a autora aponta a absoluta discriminação das mulheres: onde estão as mulheres combatentes? Por que razão é que elas não estão contabilizadas como combatentes e, portanto, passíveis de participar nos programas de reajustamento? Às mulheres combatentes não foi, de facto, dado qualquer estímulo económico, educacional ou profissional, pois foi assumido como natural que regressassem as suas tarefas domésticas, confinadas à esfera privada. Mais na sombra ainda, como nota a investigadora, estão todas as mulheres que ao longo dos conflitos estiveram ao lado dos homens nas tarefas tradicionais de apoio e que, embora não fossem combatentes, necessitam de assistência na reabilitação e integração. A outra face da moeda é a segurança, ou antes, a insegurança física ou material: no pós-conflito há uma clara transferência da violência militar do tempo da guerra para formas de violência disseminadas entre a sociedade e a família. E é essencialmente sobre elas que recai esta violência.

No plano político-constitucional, que lida com os aspectos de criação de uma autoridade política através de eleições como elemento essencial para a transição para a democracia, Tatiana Moura adverte-nos de que todo este processo é terreno tipicamente masculino, em grande medida porque é aqui que tem início a repartição dos níveis de influência e dos mecanismos de distribuição dos recursos.

No plano económico-social, que, em termos macro-económicos, se pretende desenhar como atraente para os investidores e que traz em si todos os discutíveis aspectos 
dos chamados planos de ajustamento estrutural - que nem sempre olham para a precariedade do lado social que a guerra destruiu - Tatiana Moura chama a atenção para a dimensão micro-económica, onde se situa grande parte dos trabalhos das mulheres ligados à sobrevivência diária e à economia informal.

Finalmente, o plano psicossocial, sem dúvida o mais desprezado, por ser a área mais delicada e também a menos visível, uma vez que lida com o interior das pessoas e as subjectividades. $\mathrm{Na}$ perspectiva de Tatiana Moura aqui reside o maior desafio e o maior compromisso de reabilitação efectiva de uma sociedade rumo à paz positiva. Trata-se de voltar a ver um humano naquele que o conflito desumanizou. Voltar a reconhecer-se como humano depois do que se passou, depois do que se fez para que seja possível ficar de luto pelos fantasmas da História, e então fazer a História ainda que com as assombradas visitas das "memórias da guerra".

Na perspectiva de Tatiana Moura a Agenda para a Paz de 1992 é um esforço considerável no sentido de corrigir o erro, e tentar colmatá-lo, mas, como mostra a investigadora, a lógica que a produz é ainda tradicional, masculina e politicamente estreita na sua abordagem sectorizada, nos domí- nios que privilegia, nas graves lacunas que apresenta. Não se trata, portanto, de pensar que qualquer projecto de reconstrução pós-bélica que não contemple a questão das mulheres falhará, mas, mais complexamente, que qualquer projecto de reconstrução pós-bélica que na sua definição de político, poder, violência e segurança não inclua a diferença sexual não terá sucesso porque não responde ao tecido social que pretende recuperar. Será sempre, a curto ou a longo prazo, votado ao fracasso pelo muito que exclui.

O livro de Tatiana Moura obriga-nos a mudar a escala do olhar, ao colocar o se, a que me referi de início, no mundo das Relações Internacionais e, a partir desse se, denunciar o cerco sexualizado que nos rodeia e as suas consequências, levando-nos a concluir, como dizia Maria Lourdes Pintasilgo, que "contra o cerco, não há senão uma solução. Retomar os gestos quotidianos: semear, plantar, construir, edificar, tecer." (Maria de Lourdes Pintasilgo, Graal, Notícias n. ${ }^{\circ}$ 17, Janeiro de 2005). Por isso, a conclusão do livro de Tatiana Moura não podia ser um ponto de chegada, mas antes um espaço de partida para novas navegações.

Margarida Calafate Ribeiro

\section{Meintjes, Sheila; Anu Pillay; Meredeth Turshen (orgs.), The Aftermath: Women in Post-Conflict Transformation. London: Zed Books, 2002, 258 pp.}

A criação da Plataforma para a Acção, na Quarta Conferência Mundial sobre Mulheres (Pequim, 1995) e a aprovação, pelo Conselho de Segurança das Nações Unidas, da Resolução 1325 (2000) sobre Mulheres, Paz, Segurança e Direitos Humanos constituem marcos importantes da adopção de uma perspectiva atenta à diferença sexual em todos os esforços de pre- venção e resolução de conflitos, bem como na reconstrução pós-bélica. Os discursos e as práticas institucionais, no que diz respeito ao papel da mulher no terreno dos conflitos e da reconstrução pós-bélica têm evoluído ao longo dos tempos. Todavia, existe ainda um longo caminho a percorrer. As mulheres continuam a ser consideradas, de forma estereotipada, como simples 
vítimas, como actores passivos da transformação social, e a ser relegadas para um plano secundário.

Este livro pretende ir além desta abordagem e contribuir para a criação de um novo quadro teórico de análise das experiências das mulheres nas sociedades fustigadas pelos conflitos armados. A obra, coordenada por Sheila Meintjes (Universidade de Witwatersrand), Anu Pillay (Masimanyane Women's Suport Centre e Tshwarnag Legal Advocacy to End Violence against Women) e Meredeth Turshen (Universidade de Rutgers), surge na sequência de duas conferências e um encontro. Nestes eventos, onde participaram cientistas sociais, activistas, representantes de organizações internacionais e ONGs de todo o mundo concluiu-se, em termos gerais, que não era concedida às mulheres a possibilidade de participar activamente na reconstrução de sociedades devastadas por conflitos. Prova disso é a perpetuação da violência e a marginalização por elas sofridas no pós-guerra, mantendo inalterado o quadro de relações ditado pelo sistema patriarcal. Para as sociedades devastadas por conflitos em geral, e para as mulheres em especial, o processo de reconstrução é muito mais moroso e exigente do que o fim das hostilidades.

Este livro é composto por duas partes, nas quais são abordados os problemas e os desafios que as mulheres enfrentam durante e após os conflitos armados. $\mathrm{Na}$ primeira parte, constituída por seis capítulos, apresenta-se um novo quadro teórico, que pretende revolucionar a forma como se analisa a participação das mulheres no pós-conflito. No entender das coordenadoras, grande parte das abordagens existentes tem sido insatisfatória, dado que se centra na assistência humanitária e na reorganização política, em detrimento da focalização nos direitos específicos das mulheres (direito à saúde reprodutiva, à educação superior, à participação activa na sociedade, etc.). Com vista a colmatar as lacunas destas abordagens, este livro defende a análise de alguns aspectos intrinsecamente relacionados com o papel da mulher na reconstrução pós-bélica. Antes de mais, propõe a desconstrução da unidade de análise "mulher". Não se tratando de um grupo homogéneo e indiferenciado, tem de ser contextualizado em função de outros elementos identitários, como a raça, a classe social, o estado civil, o grau de participação política, o poder económico, a condição de combatente, etc. Com esta chamada de atenção, as coordenadoras do livro pretendem trazer à luz a grande heterogeneidade das sociedades que atravessam um período de reconstrução e mostrar que parte do fracasso da intervenção das agências internacionais é explicada pelo negligenciar das peculiaridades de cada caso.

Apesar da necessidade de uma análise específica e diferenciada, existe, na opinião das organizadoras do livro, um traço comum a alguns conflitos: a existência de ganhos para as mulheres, no sentido de uma consciencialização das suas capacidades. No entanto, estes ganhos não se consolidam no período posterior aos conflitos. Durante os conflitos surgem novas oportunidades para as mulheres assumirem papéis sociais até então exclusivamente desempenhados pelo sexo masculino (nomeadamente, cargos no sector público ou formas de participação na tomada de decisão política). Não existem, no entanto, condições estruturais para a consolidação de tais ganhos no período de reconstrução pós-conflito. Por outras palavras, as oportunidades para uma verdadeira transformação social surgidas durante o período do conflito não redundam em melhoria das condições de vida das mulheres, nem significam uma alteração dos modelos das relações patriarcais. Uma das principais variáveis que está na 
origem desta não consolidação dos ganhos verificados em tempos de "paz" é a violência contra as mulheres, que persiste, embora com características diferentes, no pós-conflito. Segundo as organizadoras do livro, no pós-conflito "a violência intensifica-se porque a mulher mudou e passa a reivindicar a sua autonomia". $\mathrm{Na}$ opinião de Codou Bop, "a ausência de uma perspectiva política capaz de transformar as relações entre os sexos pode explicar a precariedade dos direitos conquistados pelas mulheres". $\mathrm{O}$ incentivo às comunidades locais (Meredeth Turshen), o combate à violência sexual, através de reformas legais e da capacitação económica e política das mulheres (Tina Sideris) e o estímulo à participação feminina nas negociações formais de paz (Sheila Meintjes) são algumas das soluções apontadas como capazes de alterar as relações de tipo patriarcal.

A segunda parte do livro consiste na apresentação de alguns estudos de caso que corroboram a actualidade e a pertinência dos aspectos abordados no enquadramento teórico e, que efectivamente, refutam a ideia de que as mulheres são meras "vítimas" dos conflitos armados. As autoras estudam a participação das mulheres durante e após os conflitos no Haiti, nos Balcãs e em várias zonas de conflito na Ásia e na África. A nota dominante desta análise é a grande diversidade e disparidade do tipo de actuação das mulheres nas situações de pós-conflito, com destaque para a criatividade e a informalidade que caracterizam a participação das mulheres na reconstrução pós-bélica.

A forma como as mulheres de alguns países do Sul da Ásia (Sri Lanka e Nepal) e da Eritreia, respectivamente, têm contribuído para a desconstrução dos "mitos" associados à participação das mulheres nos conflitos armados, através do activismo fora do âmbito familiar e da presença nas frentes de batalha, é um primeiro exemplo dessa heterogeneidade. Neste contexto, as agências internacionais poderão apoiar os movimentos sociais femininos informais, visto que estes podem funcionar como rampas de lançamento para as estruturas formais de poder no pós-conflito. A situação das refugiadas moçambicanas e sul-africanas, o papel das organizações femininas no Haiti na criação de uma sociedade mais justa e a luta das mulheres ogoni na Nigéria contra o Estado e as petrolíferas multinacionais constituem outros estudos de caso relevantes. No penúltimo e no último capítulos são apresentados, respectivamente, dois exemplos positivos de actuação das mulheres no pós-conflito: a forma original como a organização "Mother's Front" do Sri Lanka (criada nos moldes das organizações sul-americanas) utilizou as maldições, pragas e lamentações como protesto social, conseguindo, deste modo, conquistar um espaço político próprio e o apoio do público e dos meios de comunicação social, e o facto de na Namíbia as mulheres estarem representadas na política nacional (situação pouco comum nos países em vias de desenvolvimento e não só), sendo a igualdade entre os sexos um conceito que foi apropriado pelas comunidades rurais, nomeadamente do Norte do país, no período pós-colonial. Este livro, escrito e organizado por mulheres que conciliam o trabalho académico com o activismo, constitui um ponto de viragem nas abordagens sobre as mulheres e os seus papéis durante e após os conflitos. É um claro alerta para o papel chave que as mulheres podem desempenhar no contexto alargado da construção da paz e para a consequente necessidade de se valorizar as estratégias criativas (quase sempre de âmbito informal e local) que utilizam, as quais devem ser levadas em linha de conta em todas as dimensões da reconstrução pós-conflito (militar, económica, política e psicossocial, internacional). 
The Aftermath: Women in Post-Conflict Transformation é, sem dúvida, uma obra que, recorrendo a casos exemplares e interessantes, deita por terra o mito de que as mulheres são apenas vítimas passivas dos conflitos armados, apela a uma verdadeira transformação do status quo desfavorável às mulheres e abre caminho para posteriores investigações académicas na área feminista dos estudos para a paz.

Katia Cardoso

\section{Terry, Fiona, Condemned to Repeat? The Paradox of Humanitarian Action. Ithaca/London: Cornell University Press, 2002, 282 pp.}

Não podemos nunca construir o melhor dos mundos em que a nossa compaixão possa traduzir-se de imediato no fim do sofrimento, mas podemos tentar construir um mundo que se aproxime o mais possível do melhor, baseado em avaliações obstinadas de necessidades e opções.

(Terry, 2002: 216-17)

É a partir desta ideia e da sua larga experiência no terreno e na prática da acção humanitária, enquanto trabalhadora humanitária em organizações como os Médecins Sans Frontières (onde é directora de projectos) ou a Care International, em cenários tão diversos como o Ruanda, a Somália, o Iraque ou a Libéria, que a autora deste livro procura questionar os pressupostos da acção humanitária contemporânea, colocando várias interrogações: será possível, em nome de princípios morais, retirar ajuda humanitária às populações que dela necessitam? Devem as organizações humanitárias assumir as suas responsabilidades? Quais são os efeitos negativos da assistência humanitária em conflitos?

Em Condemned to Repeat?, Fiona Terry olha de forma crítica, mas muito lúcida, o papel das organizações humanitárias, assim como as consequências potencialmente negativas da sua acção nos contextos de conflito actual. Consciente das diferenças entre as várias organizações envolvidas na acção humanitária, a autora considera que estas não têm tido a capacidade de enfrentar e reconhecer um dos grandes paradoxos da sua acção: a acção humanitária tem como objectivo aliviar o sofrimento humano, mas, ao perpetuar, ainda que inadvertidamente, os conflitos, acaba muitas vezes por prolongar esse mesmo sofrimento, sustentando as forças opressivas que o causaram.

Esta obra explora de forma extremamente pertinente um conjunto de questões relacionadas com os impactos negativos que podem resultar da acção humanitária, mesmo a bem intencionada, defendendo que um dos factores mais fundamentais para a determinação da responsabilidade das organizações humanitárias é o conhecimento que estas têm à sua disposição e que lhes permite tomar as decisões necessárias. Ao adoptar uma abordagem histórica da acção humanitária e ao chamar a atenção para os seus paradoxos, Terry desafia dois grandes pressupostos do regime de ajuda internacional contemporâneo. O primeiro desses pressupostos assenta na visão de um sistema internacional pós-Guerra Fria muito mais complexo do que no passado e que confronta as organizações humanitárias com novos e extraordinários desafios. Ainda que não ignorando as mudanças genuínas da natureza dos conflitos a partir da década de 90, a autora chama a atenção para o facto de o envolvimento da ajuda nas dinâmicas do conflito não ser um fenómeno totalmente novo nem os dilemas que as organizações humanitárias 
enfrentam serem hoje mais difíceis do que os dilemas do passado. O que é reconhecidamente mais complexo é o tipo de resposta internacional às crises humanitárias, marcada por uma multiplicidade de diferentes actores envolvidos e que acabam, estes sim, por exacerbar os dilemas já de si inerentes à assistência humanitária. Olhando de forma particularmente crítica o posicionamento dos vários actores humanitários relativamente às "emergências complexas", a autora considera que os actores humanitários usam cada vez mais este conceito como uma desculpa para não terem de aprender com as lições do passado, e sobretudo como desculpa para os seus fracassos. Parece haver, de acordo com este argumento, uma tendência perversa para considerar que o que aconteceu no passado mais "simples" não é relevante para compreender e ultrapassar as "complexidades" de hoje.

O segundo pressuposto que a autora desafia, e que está relacionado com o anterior, refere-se à tendência crescente nos debates contemporâneos sobre acção humanitária para considerar este tipo de ajuda como sendo um factor de grande importância na continuação e perpetuação dos conflitos.

Ao longo da obra são, portanto, identificados e analisados os vários paradoxos e dilemas da acção humanitária contemporânea, que devem ser devidamente reconhecidos pelas próprias organizações humanitárias, para não dificultarem uma visão mais clara e rigorosa do seu potencial para minimizar o sofrimento e evitar o agravamento dos conflitos. Esses paradoxos e dilemas não são novos, sendo objecto de maior debate e discussão nos últimos anos (com a definição de uma concepção mais política da acção humanitária), e prendem-se sobretudo com a obediência aos princípios operacionais clássicos de neutralidade, imparcialidade e imperativo huma- nitário, com as questões de protecção para lá do mandato clássico de assistência conferido às organizações humanitárias e com o impacto da ajuda humanitária na economia de guerra do contexto em que actuam. Mas, contrariamente aos argumentos e posições normalmente defendidas neste debate sobre a acção humanitária, a autora defende que, para minimizar estes paradoxos, é necessário que as próprias organizações reconheçam as consequências políticas inerentes às escolhas e condições para conceder e prestar ajuda. Para que as organizações humanitárias possam responder e satisfazer eficazmente as necessidades das populações em crise, o seu comportamento deve necessariamente ser ajustado aos contextos sócio-económicos e políticos em que actuam. Partindo da análise de quatro estudos de caso bem documentados sobre o papel da acção humanitária em campos de refugiados afegãos no Paquistão, cambodjanos na Tailândia, campos de refugiados de São Salvador e Nicarágua nas Honduras (anos 80) e campos ruandeses no Zaire (anos 90), Terry explica como a ajuda prestada por organizações humanitárias a estas populações acabou, nestes casos, por ser pervertida nas mãos de combatentes, traduzindo-se em resultados humanitários extremamente negativos.

Com base nestes exemplos concretos e nas lições que deles tira, esta obra tem o objectivo claro de alertar as organizações envolvidas na acção humanitária para o facto de as dificuldades que enfrentam actualmente no desempenho das suas actividades de assistência em situações de crise humanitária não serem novas. Pelo contrário, a autora refere claramente, a partir da análise das realidades concretas dos quatro casos, que existem precedentes e experiências importantes que não podem ser ignorados e que podem contribuir para responder mais eficazmente às crises humanitárias actuais. 
Uma outra preocupação da autora é a falta de responsabilização, por partes das agências humanitárias, pelas consequências das suas acções. A insistência na definição e aperfeiçoamento de padrões técnicos no quadro da assistência humanitária tem-se manifestado contraproducente, a partir do momento em que essa ajuda passa a beneficiar o opressor e não a vítima. A ideia subjacente é que a assistência humanitária é muito mais do que um exercício técnico com o simples objectivo de alimentar ou prestar auxílio médico às populações. Nesta perspectiva, a acção humanitária é, acima de tudo, um comportamento moral baseado na solidariedade para com outros membros da humanidade. Como tal, reduzi-la a um acto puramente técnico torna-a muito mais vulnerável a qualquer tipo de abuso. É, por isso, necessário que a avaliação das consequências dessa acção tenha um peso tão importante como a intenção de ajudar. É este o passo fundamental para se passar de uma ética de resposta para uma ética da responsabilidade em matéria de acção humanitária.

Este livro obriga-nos, assim, a ir para além da ideia simplista da ajuda humanitária como algo intrinsecamente bom, desafiando também a fórmula "do no harm" (defendida no início da década de 90 por Mary B. Anderson) comum às organizações hu- manitárias, sublinhando que esta não passa de uma ilusão, na medida em que a assistência humanitária terá sempre algumas consequências negativas, e que estas tendem a ser exacerbadas pelo próprio comportamento e cultura das organizações humanitárias e não apenas pelos novos cenários de emergências complexas.

Tendo em conta estes paradoxos e dilemas inerentes à acção humanitária, o que é fundamental, portanto, é que as organizações humanitárias se empenhem em minimizar as consequências mais negativas do seu envolvimento, assegurando que as tarefas essenciais são desempenhadas sem causar mais sofrimento e reforçando as suas potencialidades antes de ampliarem a acção humanitária para além do seu alcance.

A mensagem desta obra é, sem dúvida, pertinente: a acção humanitária nunca alcançará a perfeição; por essa razão, em vez de procurar alcançar um mundo perfeito, é talvez melhor e mais seguro criar o "second-best world" que a autoria refere e ao qual nos possamos ajustar sem pôr em causa a essência do humanitarismo. Para Fiona Terry, só assim os paradoxos da acção humanitária poderão ser minimizados, evitando que as organizações humanitárias estejam condenadas a repetir os erros do passado.

Daniela Nascimento

\section{Rui Namorado, nenhum lugar e sempre. Vila Nova de Famalicão: Quasi, 2003, $104 \mathrm{pp}$.}

Considerando que a poesia que Rui Namorado nos dá a ler, neste seu último livro, partilha de concepções poéticas que encontro em alguns dos grandes poetas do continente que nos fica para lá do Atlântico, vou tentar estabelecer algumas pontes que, penso, podem oferecer uma passagem para a escrita mais recente deste autor. Charles
Bernstein, um dos pais do movimento $\mathrm{L}=\mathrm{A}=\mathrm{N}=\mathrm{G}=\mathrm{U}=\mathrm{A}=\mathrm{G}=\mathrm{E}$, nos EUA, diz-nos acerca da sua "A-poética":

A Poesia é a aversão à conformidade na procura de formas novas - ou poderá sê-lo. [...] Quando recusa a conformidade, a poesia entra no contemporâneo: falando 
para as tensões e conflitos do momento com os meios então aos seu dispor. Quer isto dizer que dou mais valor à poesia que fende o que é normal, incluindo o que afinal é normal em literatura; a poesia que faz com que seja possível ouvir sons que, de outro modo, nunca seriam articulados. (RCCS, 47: 102)

Rui Namorado traz-nos, precisamente, este tipo de aversão à conformidade, fendendo, de certo modo, o que é normal - também na sua própria prática poética. nenbum lugar e sempre é um título irónico, já que parece apontar - não para um essencialismo universalista do poético de concepção romântica, num percurso para um etéreo indizível - mas, antes, para a eterna e infinita possibilidade (que é sempre) do poético, entendido como aversão à conformidade e não aceitando, por isso, a permanência de nenbum lugar. Este é o (des)território da palavra onde Rui Namorado se encontra - e esta consciência da impermanência, inevitável à possibilidade infinita, apresenta-se dialecticamente: ela resulta do contemporâneo e, em simultâneo, "entra no contemporâneo, falando para a tensões e conflitos do momento". O tempo da palavra é o tempo da história, significando isso que mesmo o espaço provisório, o espaço "entre”, o meio do caminho entre os continentes poderosos, um espaço frágil e pequeno que pode ser a ilha - uma metáfora fundadora neste livro (a ilha "que é lugar de sul e de palavras") é "ilha de nenhum lugar": uma passagem pela passagem da história. Para Namorado, o tempo da história só pode assim constituir-se enquanto tempo da utopia, um tempo que se liberta dos nossos limites e fronteiras. Para o autor, esse é o tempo/ espaço do fazer, o tempo/espaço do acto, o tempo/espaço poiético. A raiz da criação apresenta-se como a ilha, que é lugar em trânsito da palavra, raiz do desejo pelo espaço do outro lado do oceano, lugar ao sul - o sul do mapa e o sul do corpo, que assim se vão fazendo um outro mapa e um outro corpo. Esta é a aversão à conformidade de que nos falava Bernstein: a recusa do que já é normal e reconhecível, a recusa dos limites e fronteiras das imagens/das palavras, que nos impõem a imutabilidade ilusória do presente - esta, a aversão à conformidade que procura a passagem permanente para novas formas de dizer um mundo que, incessantemente, descobrimos. Diz Rui Namorado, em "para lá do coração do nevoeiro", terceiro poema da primeira parte do livro, a parte que ostenta precisamente o título "nenhum lugar": "Para lá do coração do nevoeiro, / há uma ilha de nenhum lugar. / [...] / É um lugar de sul e de palavras, / com suave sabor a solidão" (14). E, no poema que se segue, intitulado "A Ilha" (15), descreve-se a demanda por esse lugar paradoxal onde se chega, partindo - lugar de passagem, que é preciso saber inventar. Esta ilha, pequena e frágil, tem a força que lhe permite "cerca(r) todos os horizontes": ela é a palavra, a linguagem - fora da qual nada fica. De facto, mesmo que saiamos das normas com que a organizamos e com as quais organizamos o mundo, nunca ficaremos fora dessa ilha que é a linguagem: fora de limites e fronteiras, encontraremos apenas o seu excesso, o excesso de som e de sentido, num caos por organizar.

O paradoxo apresenta-se como o traço estilístico dominante neste livro de poemas: um carácter paradoxal que nos recusa a visão linear e simplista, obrigando-nos à complexidade retórica e epistemológica da sobreposição e da manutenção dos opostos - irresoluvelmente. A metáfora fundadora da ilha é o lugar/tempo da utopia, que reside na palavra e no acto poético. Outras metáforas e motivos giram à volta desta ilha e do seu mistério: mares, brumas, nevoeiros; jogos de luz e sombra, noite e dia; 
o sul, a raiz, a espiral que nos devolve à imagem rizomática da proliferação e da origem da vida; imagens da natureza, sempre em movimento de respiração, e do vento; mas também a cidade, mais um espaço efémero a lembrar-nos a permanência dos nossos sonhos e a nossa impermanência, existencial e histórica, de náufragos (“Os Náufragos”, pp. 12-13).

A segunda parte do livro tem como título "sempre", um sempre que nos remete para o permanente recomeço e que recusa a saudade. "Sempre" implica a responsabilidade do poeta: não permanecer em lugar nenhum, em tempo nenhum, em palavra nenhuma. "Sempre" implica a aversão à conformidade, implica a permanência do caminho (para todos os lugares), como afirma o autor num poema que leva por título "Eternidade" e que termina descrevendo o lugar do poeta, de forma algo platónica e com uma leve nota de ironia: "Aqui, neste sonho,/ ao sul da memória/e sem saudade” (30). Nesta segunda secção do livro, a ideia da necessidade da (re)invenção e do recomeço, na palavra e na história, torna-se mais visível. Deparamo-nos com a necessidade da construção da origem, a lembrar a concepção adâmica de poetas como Walt Whitman (poetas que vêem o mundo com olhos de manhã) - o início de "Song of Myself" ecoado claramente em versos como "Deitam-se ao longo da relva mais verde da alma/e concentram em si todas as manhãs do mundo" (28). Tal como Whitman, em Leaves of Grass, Rui Namorado cria também, com este texto - mas também, em geral, na obra nenbum lugar e sempre - através da enumeração, um poema constituído de vários outros poemas. No caso particular, esta parte/poema, numerado com um 6 , constitui, simultaneamente, (a) uma parte do todo maior (entre um princípio e um fim, marcado pelo título no poema 4, "Uma Corça de Vento" - até ao poema 7), (b) dentro do todo que é esta segunda parte do livro (entre o poema $1 \mathrm{e}$ o poema 32), e (c) um todo em si (com o seu próprio princípio e fim). Mais interessante resulta a estratégia de sobreposição cubista dos sujeitos, permitida pela sucessão enumerada das formas extremamente curtas de cada um destes pequenos poemas de carácter epigramático. O sujeito de “deitam-se ao longo da relva", etc., lê-se já - neste momento do poema maior - como: corça, coração dos minutos, barco de silêncio, poema, pássaro azul e os séculos. Esta, a aversão à conformidade de que falamos: aquela que procura formas novas - e nunca facilmente reconhecíveis - de dizer o mundo.

O carácter imagístico dos textos, nesta secção da obra, em algumas imagens de cunho mais classicista (como a da corça, por exemplo), bem como o tratamento pontual do tema da espera e da usura, não podem deixar de nos remeter para um outro, muito amado e muito odiado, poeta do grande cânone de língua inglesa. Falo de Ezra Pound, embora a sua política esteja nos antípodas da política de Rui Namorado. Em Namorado, a usura não se pauta por concepções racistas, como em Pound, mas é subvertida na metáfora, recontextualizante, de uma natureza feita Sublime pela sua humanidade: "Está escrita nos teus olhos a usura / dos prados, dos ventos, da planície" (25). No poema intitulado "Humanidade", encontramos esta mesma placidez, algo resignada, perante os sonhos por cumprir; um olhar pacificado, que vê, na palavra, a segurança possível, tão opaca e sólida quanto possível, perante a mortalidade. Diz o poeta, num ritmo que, através da insistência na pausa, dá ênfase ao carácter sólido e opaco que acabo de referir: "As palavras retomam a sua espessura /inerte [...] Papéis aprisionam as palavras /previsíveis, exiladas, repetidas" (32). Esta presença da história é (pre)visível no nosso presente: repetimos a voz dos que morre- 
ram antes de nós, com essas palavras a permanecer em nós, exiladas. A consciência da sua presença leva o poeta a afirmar, no final do poema: "Verticais e íntimas/só as palavras resistem/ao precário sabor das coisas" (34).

O poeta sabe que a possibilidade, transportada nas palavras, nunca se esgota: essa é a sua resistência, esse é o seu inesgotável potencial utópico que se joga na íntima relação com o sujeito histórico. A imagem de força, sendo poundiana, remete-nos, contudo, para uma visão completamente diferente da história e do sujeito: uma imagem que, à permanência do sentido exigida por Pound, prefere a permanência da capacidade de resistir a qualquer sentido, sempre um "precário sabor" das coisas. O poema que se segue mostra-nos como essa resistência tem que ver com o silêncio. Não o silêncio do transcendente, do metafísico, ou do indizível. O silêncio traduz apenas a possibilidade inesgotável na linguagem. Nas palavras de Rui Namorado: "como se (se) fosse dizer", "o que podia ter sido", o "que ninguém soube dizer", o silêncio de "a palavra mais esquecida", o silêncio "dos que ficaram calados", do ainda por inventar, da revelação ainda possível (35-6). Confrontamo-nos, de novo, com a aversão à conformidade. É nessa raiz da criação que o poeta procura encontrar-se: a sul - lugar da criação - de todos os poemas, como se afirma num outro texto, "O Discreto Vestígio de um Poema" (55-6). Nesse "vago rumor", nessas "cinzas" e "labirintos", nessa promessa do" sabor dos segredos", encontra o poeta a "íntima semente" de todos os poemas (55). Não se trata da originalidade, mas da origem - como um salmão, o poeta procura o seu princípio, afirmando, noutro poema: "Semeou-se o meu sangue pelos rios/à procura das raízes e das margens" (41). A raiz é o Verbo e nele continuamos a viver. Mesmo "perdidos", habitando a ilha ao sul
(Creta, num outro poema: 56), "sendo da ilha [...] somos mar”, afirmará o poeta. Esta segunda secção de nenbum lugar $e$ sempre termina, precisamente, com dois poemas que nos remetem para um dos mitos mais conhecidos do Princípio da Criação: o encontro amoroso entre a luz e escuridão, entre o silêncio e o som - um encontro sempre renovado e eterno, que nos surge nesta sugestiva e melódica imagem do final de "Um Último Sabor": "Palavras breves no sabor dos lábios/estão agora desertas e ausentes.//E quando a noite doce as desejou,/num abraço derradeiro/inteira a luz do dia desabou" (57). Na terceira parte do livro, "Navegação das Palavras", navega-se sobre todas estas concepções poéticas e sobre todas estas imagens. O poema apresenta-se como acto, como acção quotidiana, um fazer intransitivo. O poeta, olhando para trás, limita-se a dizer: "As palavras [...] Iam sendo poema, dia a dia" (64) - e isso inclui toda a diversidade da experiência, sempre única, de cada ser humano. No quinto poema (65), os ecos platónicos, mas também os ecos de Pound, regressam: os poemas são esculpidos (como Pound pretendia), mas num artesanato da alma (a poesia, não o esqueçamos, é, segundo Platão em Fedro, uma arte psicagógica). Neste artesanato da alma se desfaz a dicotomia espírito/matéria. A "palavra mais adequada" - le mot juste-que Pound tanto almejou (a que diga exactamente, unicamente, com um só sentido, uma só verdade) transforma-se, de forma irónica em Namorado, no "silêncio mais adequado"; mas a poesia "seca e dura" ("hard and dry", dizia Pound), aquela que procura dizer o máximo no mínimo (sem excessos românticos) parece ser a mesma que Rui Namorado procura, olhando para o poema - tal como Pound olhava - como algo de orgânico e natural, como uma árvore, por exemplo: "tirando a cada frase um ramo seco" (65) 
Finalmente, apenas algumas palavras para falar da última secção do livro, que reúne alguns poemas "Dispersos". Trata-se de um conjunto mais próximo das anteriores obras do poeta: dentro da tendência de uma poesia canonicamente referida como empenhada, ou de intervenção, em que a cidade, a polis, se torna central. A relação entre o carácter mais metapoético das secções anteriores e esta secção parece-me óbvia: toda a reflexão anteriormente realizada só faz sentido se existir no âmbito da comunidade. Essa é a importância última de uma concepção de poesia como aversão à conformidade. O último poema do livro, "Tarde de Praia, ao Longe" (92), num linguagem de enorme contenção e simplicidade, apresenta-nos uma saudade transmutada em futuro: "Desce a preguiça pela tarde lenta,/nas horas o silêncio vem de longe". Este é o silêncio da história, o silêncio do que não se disse: por ser proibido dizê-lo, porque ainda não se podia, ou pode, conceber dizê-lo - silêncio do desaprovado, silêncio do não-provado, silêncio do ainda por provar. Esse silêncio está na origem de toda a palavra; no passado, que é ainda o presente e será o futuro é dessa origem, infinitamente criadora, que o poeta sente saudade, o silêncio da poesia, onde se encontram os "sons que, de outro modo, nunca seriam articulados" (Bernstein, RCCS, 47: 102)

Se há universalidade da poesia terá decerto de ser esta mesma que Rui Namorado partilha - e tem partilhado -, connosco e com outros autores, ao longo de todo o seu percurso de poeta e, atrevo-me a dizê-lo, de todo o seu percurso de vida. Nas palavras de Nicole Brossard, que são um outro dizer deste livro de Rui Namorado:

Instalar visões na língua exige uma certa lealdade para com a vida. [...] Digamos que pertenço a uma geração que cresceu com as palavras subversão, transgressão e ruptura. Estávamos no começo dos anos sessenta. O poema era uma arma para a "revolução pacífica" e para o sonho de um país que seria o Quebéque [Portugal e os anos 70, no caso de Rui Namorado]. Digamos que à questão do país eu preferia a escrita e os seus reflexos lúdicos, imaginando "o prazer do texto" como um dado político susceptível de aumentar as nossas hipóteses de felicidade. Sim, misturei muitas vezes política, texto e escrita e nunca me arrependi disso. [...] - o fragmento, a elipse, a velocidade desde as primeiras palavras, o poema acelera os batimentos do coração. Trata-se é claro de dar um sentido à vida. Digamos que é preciso saber como replicar, não se amedrontar perante o nome assustador das permutações semânticas sempre prontas a fazer nascer em nós um gosto pela luz e o excesso.

Escrevo para fazer acto de presença na língua. (RCCS, 47: 146-7)

Graça Capinha 